\title{
Pollution Caused by Humans: A Curse on
}

\section{Animals}

\author{
Sanchi Gupta ${ }^{1}$, Aakarsh Tomar ${ }^{2}$
}

${ }^{1}$ BBA-LL.B. (Hons.), G.D. Goenka University, Gurugram, India

${ }^{2}$ BA- LL.B. (Hons.), G.D. Goenka University, Gurugram, India

\begin{abstract}
The study explores the pervasiveness and causes of Pollution causing detrimental impact on health conditions of animals finally leading to increase in the death ratio of animals in the country. Pollution can be of various types such as Air pollution, Noise Pollution, Water Pollution and so on. These types of Pollution are caused due to the release of Hazardous Chemicals in our environment and by the improper activities done by the human beings in the society. On the contrary a complete on Pollution within the country would not be possible, but a conscious effort needs to be there to save our Country and its human beings and animal species. Already there has been a huge increase in the death Ratio of animals in the country from past decades. There are various ways in which Pollution within the Country can be managed and reduced such as walking smaller distances than using vehicles causing pollution, not throwing garbage particles in the water bodies, eating plant based diet and not slaughtering animals(which is major cause of pollution in environment). This research paper tends to strike the drastic damage caused to life of animals due to pollution by taking some universal essentials and also show their preclusion.
\end{abstract}

Keywords - Hazardous Chemicals, Increase Death Rate, Animal Slaughtering, Damage.

\section{RESEARCH QUESTIONS}

1. How far is the pollution causing detrimental impact on health of Animals?

2. What is the effect on animals in present and what will it be in the future due to pollution?

\section{RESEARCH METHODOLOGY}

The researcher in the following research paper has adopted the Doctrinal Research Method. The researchers have collected the primary sources from the various policies and acts prevailing in the country and the secondary sources are from the various books, articles, documentaries and decided case laws using library and net sources.

\section{INTRODUCTION}

The protection of environment is a global issue which is not an isolated problem of a particular area or a nation, rather is a problem that prevails everywhere. The problem of pollution in the environment is one the increasing concerns among all the countries irrespective of their size or ideology. This problem doesn't depend on the level of development in the country and also this problem is not new in its origin.

Environment in the world is one of the most important and the beautiful aspect. As per Section 2(a) of the Environment Protection act, 1986 our Environment is comprising of interrelationship and the interdependency between land, air and water with the human beings, plants and Animal Creatures (land and aquatic animals).

Our Environment is a complex system as it is the combination of both physical as well as chemical factors. The physical factors comprise of land, air and water that provide the basic means for sustainability in the country and on the other hand chemical factors are the gases that are being released in the environment.

Unfortunately in this beautiful aspect of the world a lot of pollution is being caused by the human beings. Pollution is being defined in Section 2(c) of the Environment Protection Act, 1986. According to this section environment pollution means the presence in the environment of various environmental pollutants.

This diagram (figure 1 ) denotes various types of environmental pollutants as per Section 2(b) of the Environment Protection Act, 1986 that tend to be injurious to the environment. Pollution in the environment is causing a lot of damages and imbalance in the society which is ultimately causing a detrimental effect on the living conditions of animals in the society. 


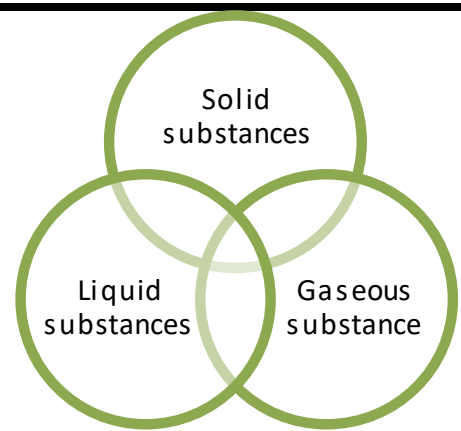

Fig.1: Various forms of Pollutants in the environment as per Environment Protection Act,1986.

Pollution in the environment is caused due to various factors and also by the day to day activities of human beings in the country. On contrary these day to day activities of the human beings are important as there these activities are helping them to earn their livelihood and is also causing an increase in the GDP of the Economy, so a complete on these activities would not be possible. Due to these activities in the economy there is a lot of contradiction in the environment which is further reminding the authors about the conflicting approach being discussed under the Stockholm declaration.

According to the Stockholm declaration approach there must be proper harmony between the sustainability and the development in the environment. In the modern era there is no proper harmony being done to the environment. People are only being concerned about benefiting their own lives and are least bothered about the conditions of others. People in today's world are only looking towards the merits and the opportunities they can prevail for themselves and fail to look towards the harm they have been causing towards the Animals

This negligence in the society is causing a detrimental impact on the living conditions of the Animals in the present and if continues will also cause impact in future.

\section{CAUSES OF POLLUTION}

Some of the major causes of environmental pollution are as follows:

- Vehicles used to ply from one place to another.

- Industrial activities being conducted by the humans for the welfare of the humans in the locality.

- Slaughtering of animals because when the animals are being slaughtered then there is huge amount of methane gas being released in the environment causing pollution and due to this pollution health condition of animals are getting spoiled and animals becoming endangered. According to the documentary film by Louie Psihoyos (Oscar Wining Director) methane gas released in the environment by slaughtering is 86 times more destructive than the Carbon Dioxide and Nitrogen gas being released from the vehicles.

\section{EFFECTS OF POLLUTION ON ANIMALS - AN OVERVIEW}

Pollution in the environment has been causing a great effect on the living as well as the health conditions of the animals. Authors herein have tried to bring a light on the same through various reports and submissions.

- According to the report in 2017 by Sciencing, it has been accessed that many species have been experiencing huge pollution events till date which eventually has been causing them death or a threat towards their habitat.

This report also shows that there are huge oil spills in the water bodies by the human beings which has been causing death toll to the animals and species residing in the oceans. According to the report more than $1,00,000$ sea birds have died till date and it has not stopped. Also there have been more than 144 bald eagles that have also died till date.

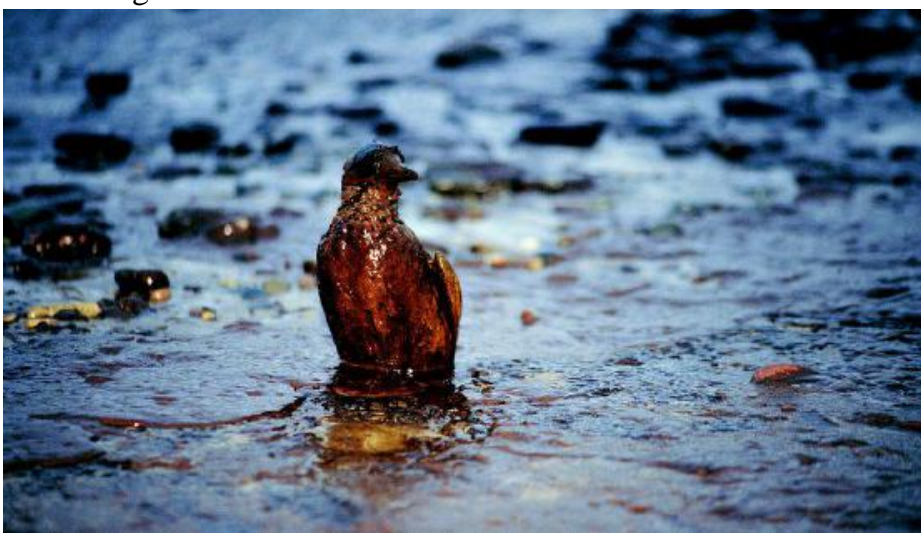

Fig.2: Animals beings effected because of chemicals and oil spills in water bodies

- According to the report by $W W F$, the increased amount of pesticide spray being done on the crops by the farmers to control the pesticides has been causing mutation and fertility problems in the animals. This report also shows that these chemicals can also be found in the blood of the native animals residing in the nearby areas. Also there has been a report of Sciencing in 2017 which shows that the synthetic chemicals being used to control pesticides 
are highly destructive to the animals. These chemicals are causing a reproductive system failure and also neurological effects on the animals in the environment.

- Not only is this but there are times when we ourselves have witnessed that the animals are dying due to the waste we humans have been throwing around in the locality. There are various plastic bottles and jars thrown around which gets attached to the animals causing deep cut on the body of animals finally leading to the death of the animals in the environment. It is mainly because of the uncompleted food being packed in the plastic bottles thrown up randomly attracting these animals towards those food bottles and containers causing them injuries.

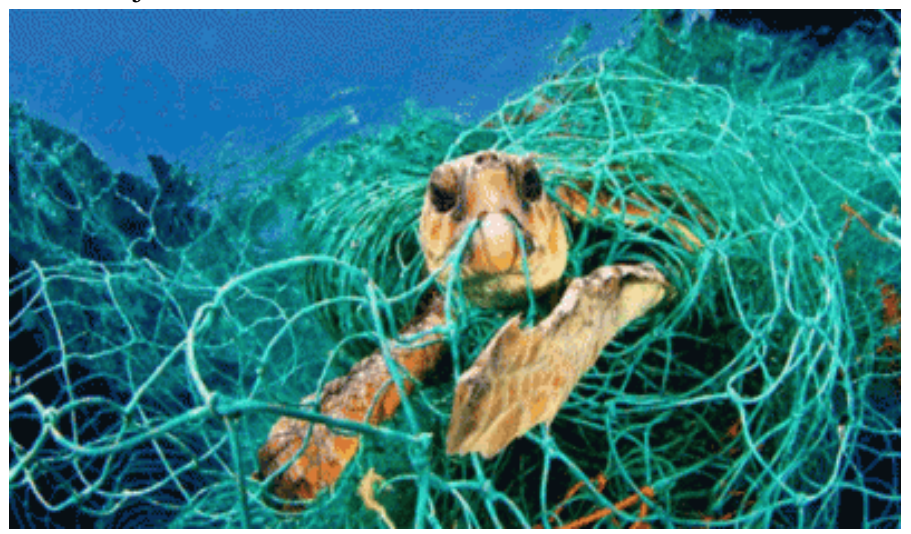

Fig.3: Shows animal getting trapped in the garbage thrown by humans

- According to the WWF report there are a lot of waste particles that are thrown into the water bodies by humans that it has become so much polluted that living conditions for animals have become difficult. According to the report around 2.4 billion people along with the aquatic animals have been suffering.

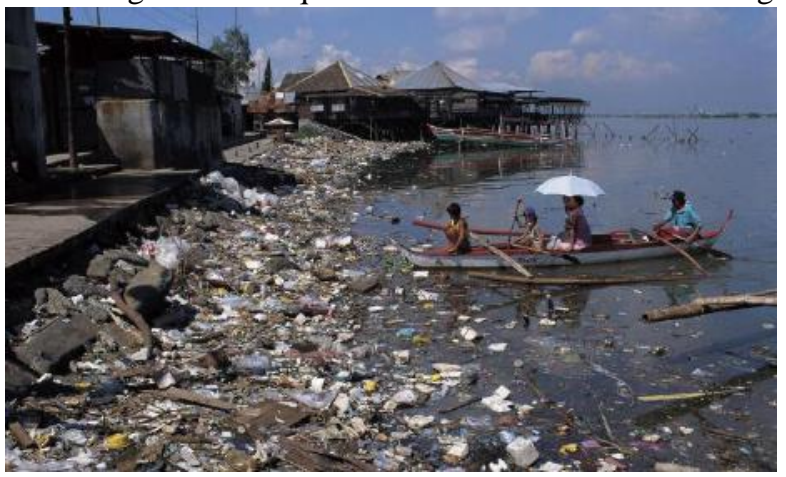

Fig.4: Depicts most of the garbage in water bodies is by plastic waste Locality
- Not only this rather there is a report by One Green Planet, which shows that $90 \%$ of the garbage in the water bodies is by the plastic being thrown in the locality. This report says the plastic does not decompose entirely and the particles break into small microscopic plastic this has been causing a detrimental impact on the marine wildlife. Plastic in the water gets stuck around the animal's body causing them suffocation, dehydration, starvation eventually leading towards death.

These reports tend to bring to the notice need and importance of reducing pollution in the environment in order to safeguard our society and the animals residing. It is a high time that we showcase our responsibilities towards the protection of our environment. Without animals in the environment it would be difficult for us also to stay alive as we are all dependent on each other. If not for the sake of animals then at least for our own sake we should try to avoid polluting the environment.

\section{LEGAL REMEDIES AVAILABLE TO ANIMALS IN INDIA}

India is having amazing laws and principles which are legally bound to be followed. These laws and principles are to be followed in order to prevent our environment and animals living in the environment. Some of these laws and principle are as follows:

- First and the foremost remedy available for the protection is Article $51 \mathrm{~A}(\mathrm{~g})$ of the Constitution of India. According to this article we the people of India should be compassionate towards the animals living in the Environment. This remedy has been interpreted by the authors because as human beings we should not indulge in the activities that use plastics because usage of plastic is causing a detrimental impact on animals. If we human beings are using plastic then we are not being compassionate towards the animals and are also causing violation of our fundamental duties towards the animals .

- Secondly as per Section 428 and section 429 of the IPC 1860, it is a criminal offence to kill or to cause injury to any of the animals residing in the environment (includes stray animals).

- $\quad$ Thirdly as per the PCA 1960, if there is any form of sudden abandoning of any animal then as per Section $11 \mathrm{j}$ (i) of the act there can be an imprisonment for a period of three Months. 
- $\quad$ There are principles as well in the society that acts as a form of remedy to prevent animals and the environment. One such principle is Polluter's Pay Principle. According to the above mentioned principle polluters have to bear up the entire cost of causing pollution in the environment. This principle helps to collect the funds in order to protect the environment also this principle in same way or the other helps to reduce pollution which is leading to a form of protection for the animals in the country. The concept of this principle was best laid down in Shri Ram Gas Leak Case in 1987.

- Also if there is no sufficiency of food being provided to the animals we are keeping as pets in our homes then also as per the PCA 1960 there can be an imprisonment for three months.

The authors have figured out that there is a gap in the Legal System of the country. There are remedies that are being available for the protection of animals in the country, but since there is inadequacy of laws thus human activities that are leading to direct/ indirect death of animals are not getting penalized.

Thus there should be petitions filed for the protection of Animals by proper monitoring of the activities also various other governmental activities should take place in order to maintain proper harmony between the development and environmental sustainability.

\section{RECOMMENDATIONS}

The authors have discussed how various kinds of pollution in the Environment have become a curse of the lives of animals. If this form of pollution in the environment continues to prevail then that day is not far when the existence of animals would be rare. Already many of the animals have extinct from the country and many are on the verge of getting extinct from the country. Thus in order to avoid such an incidence in the country authors has tried to mention few of the recommendations to protect the animals in the environment. Some of the recommendations are as follows:

- We all should try to be self- conscious and should try to prevent ourselves from using harmful substances in the environment that are causing effect on the living conditions.

- Try using eco friendly products in the environment.

- Plastic recycle bins should be placed in the locality so that plastic bottles and cans are not littered here and there rather those plastic products are recycled immediately. This action would prevent animals from getting injuries from plastic cans and bottles.

- There should be replacement of plastic bags with the handmade paper bags and these bags should also be reused and recycled.

- $\quad$ Try to promote sustainable living by educating and conducting workshops and seminars in schools and also in other locality areas.

- There should be appointment of staff members by the municipality and the government for the regular cleaning up of litter from land as well as from the water bodies. There should also be an appointment of other staff members to look after the activities of the current staff members.

- Save energy when not in use as it will reduce the amount of particle emission in the environment and animals could breathe in a better air.

- Try to make sure that the gas stoves are well ventilated so that there is no much smoke in the environment and the throat of the animals would also not be chocked.

- Proper waste management system should be there in the locality in order to manage the waste production in the locality. Also monitoring of waste in industrial sector to be done to avoid causing harm to aquatic animals.

- There should be proper and effective replacements for the harmful chemicals and substances in the environment.

\section{CONCLUSION}

Pollution in the environment is causing a detrimental impact on the living condition of the animals in the country. Though pollution in the country is having an immense impact on the environment but a complete on this pollution in the country is also not possible. There are human activities in the locality which even after various preventive measures are causing an indirect impact on the environment. There are various principles and laws in the country that are working to bring peace, sustainability and development in the country, but these principles and laws alone are not sufficient to overcome the prevailing situation of the country until and unless the huge mass doesn't join hands together.

Even in the modern era of today where there is proper well developed and well organized technological sector there still prevails a sector where people are not aware of the fact 
that their day to day activities are causing a degradation in the environment and instead of understanding their responsibilities towards the environment they are more concerned about their own living conditions and their own welfare. People in today's era fail to understand that environment in which they are living is not their birth property rather they are sharing it with many others as well so it becomes their duty to protect them as well. People's activities in order to gain more comfort is not only causing an impact on living conditions of animals but is somewhere or the other also causing an impact on their own living conditions.

It's never too late; hence we should all try to find a permanent replacement to such a problem, Thus in order to fix the prevailing condition of the country and to bring peace, harmony and sustainability strong preventive measures to be taken up by the government and also by the people themselves.

\section{REFERENCES}

[1] The Environment Protection Act, 1986.

[2] The Stockholm Declaration, 1972.

[3] Louie psihoyos, "Cowspiracy: the Sustainability Secret" $<$ https://g.co/kgs/ua5WGE $>$ (Initial Release: 26 June 2016) accessed 20 May 2019.

[4] Catherine Armstrong, "Pollution's Effect on Animals" (Sciencing, $24 \quad$ April 2017) $<$ https://sciencing.com/pollutions -effects -animals5292091.html> accessed 20 May 2019.

[5] Jordi Chias, $<$ https://www.nationalgeographic.com/magazine/2018/ 06/plastic-planet-animals-wild life-impact-wastepollution/\#/plastic-waste-single-use-worldwideconsumption-animals-4.jpg> accessed 18 May 2019.

[6] "Threats and Pollution" (WWF) <https://www.worldwildlife.org/threats/pollution> accessed 20 May 2019.

[7] The Constitution of India

[8] The Indian Penal Code 1860

[9] The Prevention of Cruelty Animals Act 1960

[10] M.C. Mehta V. Union of India (1987)

[11] The Prevention of Cruelty Animals Act 1960

[12] Human Society International, "Animal Rights in India that Every Citizen Should know" (19 February 2016) <https://www.thebetterindia.com/46721/> accessed 19 May 2019. 